\title{
When Eastern organisational cultures meet Western economies: some potential impacts
}

Jose Areekadan

Harbin Institute of Technology,

School of Management,

92 West Dazhi Street, Nan Gang District,

Harbin, Heilongjiang, China

Email: areekadanj1@cnc.bc.ca

Email: jareekadan@outlook.com

\begin{abstract}
Eastern organisational relationships and networks have been well documented and researched extensively by numerous organisational theorists. This paper reviews the existing literature on the concepts of 'guanxi' and 'wasta' and considers the potential economic impact to a Western economy. Similarities and difference between guanxi and wasta are explored in order to determine what the potential level of influence may be to the Canadian economy. It concludes that neither guanxi nor wasta have a significant impact on the Canadian economy based on Canadian inward foreign direct investment.
\end{abstract}

Keywords: organisational; culture; guanxi; wasta; nepotism; Canada, economy, FDI.

Reference to this paper should be made as follows: Areekadan, J. (2022) 'When Eastern organisational cultures meet Western economies: some potential impacts', Int. J. Cultural Management, Vol. 1, No. 1, pp.80-91.

Biographical notes: Jose Areekadan holds a BA in Political Economy from the Concordia University of Edmonton and MBA in IT from the Dalhousie University. He is currently a PhD student at the Harbin Institute of Technology and works for the College of New Caledonia as an Associate Dean. He has also worked for UNICEF in East Jerusalem, occupied Palestinian territories as the emergency education coordinator. He also worked with the Afghan National Security Forces as part of the Canadian Armed Forces NATO mission in Kandahar, Afghanistan as an Infantry Captain. He has taught at post-secondary institutions in Canada, Bahrain, China, and Russia. He has travelled extensively as a result of his international employment and has language abilities in Malayalam, Arabic, and Mandarin.

\section{Introduction}

This paper will first look at the significance and influences of culture in China and countries of the Middle East region in an effort to understand the origins and beginnings of how guanxi and wasta evolved to be recognised as a key component in Eastern organisational relationships and networks. The author of this paper has worked extensively in both regions and has shared his experiences from a Western prospective. Aspects of Chinese and Arab culture to appreciate the relevance of culture on guanxi and 
wasta contrasted and compared. Eastern and Western business relationships will be compared to understand why guanxi and wasta are necessary and what purpose they have within their respective countries. The concept of legitimacy in China and the Middle East will also be discussed to demonstrate how guanxi and wasta are key to the achievement of legitimate business practices in their respective countries. Guanxi and wasta will be analysed individually and compared to the Western concept of nepotism. Finally, statistical data will be presented to illustrate the potential extent of influence of guanxi and wasta on the Canadian economy and the potential impact on Canada's ability to conduct international trade with both China and countries from the Middle East region in the future.

\section{Significance and influences of culture: China and the Middle East region}

Before an examination of linkages between Eastern organisational relationships to Western organisational relationships and what the resulting influences may be to a Western economy such as Canada, the significance of culture on Eastern and Western organisational relationships and networks must first be appreciated. The importance of Eastern culture on organisational relationships is significant in both China and the Middle East. Culture is deeply entrenched in the management of local companies within each region.

Religious traditions are heavily intertwined with Middle Eastern culture based on the origins of Islam (Wolf, 1951). Islam is pervasive throughout Middle Eastern cultures as it is the dominant religion in the Middle East region. Islam influences the established governments of Islamic countries that make up the Middle East region. Sharia Law is derived from Islam and is the basis for the judicial and banking systems for Middle Eastern countries (Baamir, 2016). Islamic religious traditions Middle Eastern culture, and Middle Eastern organisational relationships are interconnected. Religious practices are openly observed and encouraged in Middle East workplaces as part of the mainstream culture. For example, it would not be uncommon to see employees of Middle Eastern organisations immediately stop what they are doing, fall on their knees to adopt a prostrate prayer position, and begin to pray out loud in full view of waiting customers. This type of workplace behaviour is within acceptable cultural norms and to be expected throughout the region (Katz, 2013). There are five loud audible calls to prayer that happen at regular intervals throughout the day. The calls to prayer are made according to the space orientation of the sun and one's position on the ground. Many businesses in the Middle East have operating hours that would include at least some of the calls to prayer.

In comparison, public worship as it is practiced throughout the Middle East would not be as readily accepted in China. Chinese nationals generally do not demonstrate their religious practices outwardly (Yao, 2007). Those that do follow an organised religion tend to reveal their devotions in a more subtle manner with greater importance placed on religious symbols in their homes or businesses. These cultural religious practices may seem strange to observers from Western countries but are accepted cultural norms in the Middle East and China. Religious practice influences culture and organisational relationships within China and the Middle East. 
The last meaning of culture takes its roots from the study of anthropology, symbolism, and metaphors. Organisational cultures share meanings and symbols among their membership. Unique corporate language can develop within an organisation that is not easily understood by others outside the organisation. Most citizens of China are Buddhist, and as such it would not uncommon to see statues of Buddha alongside burning incense and a gift offerings space in a local restaurant (Yao, 2007). Symbolism is very important to Chinese culture. Certain symbols hold a significance to business organisations. For example, a statue of a frog is said to bring luck wherever it is placed. Likewise, the statue of a cabbage is said to bring wealth wherever it is placed. These statues are often placed conspicuously at entrances of business establishments where it is believed to have the greatest impact for the organisation. The Chinese also give increased value to the number eight over other numbers. The number eight is believed to be a lucky number and many Chinese business owners will try to incorporate the number eight into the names of their businesses with more multiples of the number eight equating to more multiples of luck. For example, in North America, 'A1' is a prefix that is often used to name a business. The reason for the A1 prefix is more practical. Using A1 in an organisational name will result in a first listing in a Yellow Pages business directory (Fernandez and Rosen, 2000). The Yellow Pages directory listing used to be the primary method for customers to connect with businesses that they were seeking services from. The number eight or multiples of the number eight are used in a similar fashion but has a more cultural and symbolic importance in China (Harrell, 1979). Such symbols are easily recognisable by customers in China and are familiar to them. Familiarity with these cultural symbols could be used to build organisational relationships in China.

Symbols used to represent Western organisational relationships tend not to have religious relevance. Western culture is comparatively more secular in this regard and emphasises the separation of religion between church and state (Modood, 2010). The fact that Western countries are much more ethnically diverse than homogenous China or the Arab majority populated Middle Eastern countries, accounts for the lack of a single strong cultural identity based on ethnic origins. Western culture-based organisations do use symbols but, in a completely different manner. For example, the usage of corporate logos could be representative of Western organisational culture symbols. Social media organisations such as Facebook, Twitter, and Instagram all use widely recognisable corporate logos that do not have noticeable religious or cultural significance but are unmistakably the cultural symbol of the respective organisation. Corporate symbols are pervasive throughout Western culture and are a non-verbal communication method by which to define an organisation. Such logos and are encountered frequently and daily with effective corporate marketing and advertising techniques. Corporate logos are familiar to Western customers and can be used to gain trust and build customer loyalty. Social media platforms allow users to sign-in or log-on if they are users of another recognised social media platform. A potential customer encounters a corporate logo symbol as a visual cue. This is a means to encourage the customer's participation.

Cultural symbols are conceptual shortcuts that convey ideas such as power, quality, influence, reverence (Flannigan, 2014). Symbols can be powerful images that have an ability to evoke strong human emotions. For example, consider the way a country's flag can instil feelings of pride and nationalism. Consider how the same flag could also compel another person to be angry and hateful of who or what that flag represents. 
The very same symbols can even bring about sadness and sorrow for others when they witness a national flag draped over a coffin of a fallen soldier (Areekadan, 2014). The usage or non-usage of cultural symbols can be used by organisations to evoke customer participation. For example, a product with an American flag could prompt a potential customer to purchase a product in the USA because it instils national pride and patriotism. The same American flag could prompt another potential customer from another country to boycott that product because of what the cultural symbol means to that customer.

Evidently, the importance and reality of organisational culture is significant. Without careful consideration for culture as it relates to organisational relationships and networks, organisations would be unidentifiable to potential customers as they are now, and international business would be fraught with insurmountable hurdles. A deepened understanding of Eastern culture and organisational relationships could provide for greater profit potential in Eastern markets when used strategically for the benefit of the Western organisations. Culture is a powerful tool to wield. The above examples show how it can be employed to shape organisations both internally and externally. When organisational culture is understood correctly, it can be used strategically to achieve much more than just financial gain. History has shown us that the importance of organisational culture is not limited to that of the corporate world. Culture can be used to win the hearts and minds of people because of if its anthropological roots and the deep connections to our beliefs and value systems (Areekadan, 2014).

\section{Eastern and Western business relationships}

Business relationship development is the process of establishing, developing, and maintaining relationships (Berry, 1983; Ford, 1980; Gronroos, 1994). Business relationships between people in Eastern cultures are complex. In both Chinese and Arab cultures, the purpose of brokering relationships in business is based on a strategy of reducing risk and uncertainty while adding value to the organisation by means of prospective future business transactions. The core value of the business relationship is built on the foundation of mutual understanding and trust between all participants. Such business relationships can then potentially yield an increase in organisational profits which would then encourage the continuation of the business relationship.

This is different from business relationship development in Western countries. Business relationships in Western cultures are more formal and are more commonly referred to as a networking activity with a mutually understood beginning and end to the relationship. Generally, the business relationship or networking activity extends only as far as the business transaction itself. Once a transaction is made, the relationship is not necessarily expected to continue further. There are usually no expectations that a business relationship should be carried over into the participants' personal lives. In comparison to business relationships in the East, the Western equivalent could be regarded by Eastern observers as more superficial and less personable than the concepts espoused in guanxi and in wasta. 


\section{Legitimacy}

In the Merriam-Webster Online Dictionary, the word legitimacy is defined as:

"(1) allowed according to rules or laws; and (2) real, accepted, or official"

(Legitimacy, n.d.).

The term legitimacy most commonly refers to the right to exist and, in the context of this comparative study, to perform business activity in a universally accepted manner. If an organisation lacks legitimacy within a network, the ability of an organisation to pursue its goals and accumulate resources can substantially be reduced (Dowling and Pfeffer, 1975). Organisations that do business in either China or the Middle East must first seek legitimacy where they do business. It is not unreasonable to expect that local businesses and government understand the financial benefits of hosting foreign organisations in their respective countries. It is also not unreasonable to understand the view by organisational leaders that a host country should abide by standard international business protocols to receive the resulting financial benefits. Unfortunately, there are no real international standards or universally accepted business protocols that will result with an identical result of Western legitimacy status for most business operations in China and the Middle East.

The attainment of legitimacy in Western countries is markedly different from Eastern countries. Legitimacy in China is generally gained through guanxi, while legitimacy in the Middle East is usually garnered through wasta. In the online Collins Dictionary, the word guanxi is defined as "a Chinese social concept based on the exchange of favours, in which personal relationships are considered more important than laws and written agreements" (Guanxi, n.d.a). In the online MacMillan Dictionary, the word wasta is defined as "influential or powerful social connections than an individual has" (Wasta, n.d.). This has been demonstrated by the initial failures on the part of several Western organisations such as McDonalds in Middle East and Carrefour in China. Organisations that are native to China or the Middle East understand the mechanism of legitimacy in their respective countries. These local businesses have thrived using these systems of organisational relationships and informal networks for hundreds of years. It not until Western organisations sought to understand why they encountered resistance where they expected enthusiastic acceptance by Eastern host countries that they began to use the same informal networks and business relationship building activities in China and in the Middle East.

Ahlstrom and Bruton suggests there are three forms of legitimacy. The first form is a resource-oriented view of legitimacy. This view of legitimacy focuses on the cost-benefit evaluations of an organisation's business activities by those involved in informal networks (Wood, 1991). If the perceived value of a business transaction is significant enough, then legitimacy is granted. This could potentially occur with the initial entry of an organisation into China or the Middle East region. The second form of legitimacy is a moral-based view of legitimacy that forms legitimacy by public perception (Suchman, 1995). This form of legitimacy could potentially manifest itself through religious views in the Middle East or sentiments of nationalism inspired by the ruling communist party in China. The third form of legitimacy is based on the relationship between the organisation and its cultural environment. This view represents the following of cultural norms and whether an organisation's business activities can be accepted by people of the local 
culture. This third form of legitimacy is what the concepts of guanxi and wasta can harness in a unique way that would otherwise not be possible in Western countries.

\section{Guanxi}

Guanxi has many meanings. The World Learner Chinese website defines the word Guanxi as:

"(1) personal connection between two people in which one is able to prevail upon another to perform a favor or service, or be prevailed upon and the two people need not be of equal social status; (2) a network of contacts, which an individual can call upon when something needs to be done, and through which he or she can exert influence on behalf of another; (3) a state of general understanding between two people: he/she is aware of my wants/needs and will take them into account when deciding her/his course of future actions which concern or could concern me without any specific discussion or request" (Guanxi, n.d.b).

Guanxi is a central idea in Chinese society and has become increasingly pervasive throughout Southeast Asia wherever there are international Chinese business interests. Outside of mainland China, guanxi is sometimes also referred to as the 'bamboo network' (Chaminade and Vang, 2007). The word guanxi describes the idea of a dynamic organisational relationship and a personalised network of influence. In the English language, guanxi translates roughly into the words 'connections' and/or 'relationships'. However, neither of these words in English really reflects the profound Chinese cultural implications that guanxi represents.

Guanxi refers to the benefits gained from organisational relationships and personal networks. It is not unusual for Chinese people to develop a large number of guanxi relationships that expand in a web of different directions. Some guanxi relationships can potentially become lifelong relationships. Reciprocity of personal favours is a key component to maintaining a guanxi network. The more favours you ask of someone the more favours you owe them. Guanxi relationship can sometimes perpetuate a never-ending cycle of favours (Ostrowski and Penner, 2009). The failure to reciprocate a favour asked is considered a cultural 'loss of face' or 'mien tzu'. Loss of face in China is a reference to prestige, propriety, and social status. 'Loss of face' is a great dishonour in China and most Chinese will go to great lengths in order to preserve their prestige, propriety, and social status. There is a cultural understanding in China called 'renqing' that describes the moral obligation people have to uphold their guanxi relationships.

The network of guanxi usually extends from family, classmates, work colleagues, and members of common social circles or organisations in a manner that is similar to the Middle Eastern approach to wasta. Maintaining close and constant communications with members of a guanxi network is not necessarily required in order to justify the obligation of reciprocity. The relationships formed by guanxi are personal and not transferable (Fan, 2002). Economists have warned Western countries, such as Canada, that want to increase their trade with China, to improve their 'cultural competency' in regards to practices such as guanxi, to avoid business relationship failures (Smart, 2012).

In China, the boundary between business and personal lives can sometimes be blurred as people tend to rely heavily on their closer relations and friends. This can result in nepotism in the work force as it is common for authoritative figures to draw from family 
and close ties to fill employment opportunities, instead of assessing talent and suitability which is the norm in Western societies. This practice often prevents the most suitably qualified person from being employed in the position.

\section{Wasta}

Wasta is used extensively throughout the Middle East region. While there are many similarities to guanxi, it is based almost exclusively on immediate and extended family relations. The reasons for the familial focus of these relationships is most likely rooted with the tribal origins of modern Arab families. Arab families were organised into tribes and relied heavily on the bonds the kinship that were formed in order to survive their sometimes austere desert environments. This tribal-based kinship has developed into what is known as wasta today and is now employed as a means for their family members to survive and thrive in competitive business environments.

At first glance wasta appears to be the Middle Eastern version of Western nepotism. While wasta may fulfil many aspects required to meet a criterion for nepotism, there are some unique differences. The focus on family is much greater in the Middle East region than it is for Western countries. The family bond is an extremely strong value for Arab culture. At one time, it could mean the difference between life and death for a family. Today the family bond is a cherished honour that is similar in significance to the Chinese concept of 'face'. For example, it is not uncommon for families to live together in the same home for many generations. When the opportunity arises to leave home, most Arab families will choose to remain living in the vicinity of other immediate or extended family members to maintain their family bonds. Immediate members of Arab families are generally larger than their Western counterparts. Wasta also pertains to extended families or close friends of family. The Arab extended family can be significantly large in numbers. For example, the ruling family of the Kingdom of Bahrain (the Al Khalifa family) has approximately 2,000 members (as of 2007). In comparison, the ruling family of the Kingdom of Saudi Arabia (the Al Saud family) has approximately 20,000 members (as of 2007).

Wasta is also heavily dependent on the idea of trust or shura. In a situation where an individual in the Middle East region wanted to complete a business transaction, that individual would have to place a great deal of trust in the other party. While the idea of trust in business transactions may seem to be a universal concept, it is not the case in the Middle East region. Generations of tribal wars based on rival family feuds necessitated the reliance of maintaining business transactions within the family whenever possible. The use of wasta can almost be considered a form of guaranteed trust in business transactions. Both parties likely know each other and may even be related. Therefore, the consequence to breaking this trust and reneging on a business transaction in any way is far too great and it would be considered an attack on the family bond. Such an action would contravene Arab cultural norms and values as it is considered dishonourable to the family. For this reason, wasta is seen as a reliable intermediary, much like PayPal is employed by customers who engage in online shopping. 


\section{Nepotism}

There is ample evidence and research to suggest that nepotism brings many problems with it (Stewart, 2003). This is problematic for those that believe guanxi and wasta are simply the Eastern form and practices of nepotism. If it is true that guanxi and wasta are merely the Eastern form and practices of nepotism, then it must be understood that a whole set of cultural norms and values have been put in place to justify it in their existence. Nepotism has a pervasive negative connotation in Western countries (Sidani and Thornberry, 2013). It is often perceived as a system that uses a non-objective measure based on key relations rather than objective measure such as skills or professionalism (Yeung, 2000). Whether or not this true of either guanxi or wasta, the fact remains that both guanxi and wasta are extremely widespread and their influence grows as more countries like Canada seek to increase international trade and business with China and oil rich Middle Eastern countries. The concepts of guanxi and wasta are simply far too entrenched in Chinese and Arab culture to attempt to eliminate them altogether. Facing this reality, most organisations have instead chosen not to go against the grain and to work with these local networks instead. By participating in organisational relationship building and expanding the network of the organisation in China and the Middle East region, organisations are increasing their competitive advantage.

\section{Significance and business impact to the Canadian economy}

Canada's largest trading partner is the USA. The USA accounts for more than $80 \%$ of Canada's international trade. This high percentage of trade is mainly due to the close proximity of the USA as an international trading partner. While it is widely recognised that it would be more advantageous for Canada to diversify its international trade with other countries, the logistical reality remains that the USA is an ideal trading partner based on its geographical accessibility to Canada. Even though Canada is separated by oceans from China and the Middle East, Canada is currently investing in infrastructure that would allow it to sell Canadian natural resources to countries other than the USA. For example, Canada is actively trying to expand its oil pipelines to the west coast of British Columbia in order to facilitate the sale of crude oil to countries such as China and India. Canada has also relaxed its foreign ownership policies to allow for greater foreign direct investment (FDI). For example, the Calgary-based oil company Nexen was purchased by the state-owned China National Offshore Oil Corporation in 2013.

To determine the influence that both guanxi and wasta could potentially have on the Canadian economy and organisations, it is necessary to determine how much business is influenced by organisations and people that are from these specific regions of the world. There are several ways to determine the significance and business impact to the Canadian economy. For the purposes of this paper, FDI data and statistics have been primarily utilised. Table 1 compares FDI figures from different countries including China and countries from the Middle East region. Large amounts of FDI indicate more significance and the potential for greater business impact to the Canadian economy, while lower amounts of FDI indicate less significance and a lower risk for potential business impacts to the Canadian economy. 
By analysing FDI data and statistics in Canada (Table 1), we can determine how much specific countries contribute in terms of direct investment dollars to the Canadian economy. While FDI data and statistics are made readily available by the government of Canada to the general public, FDI results are limited to accurately showing only the past and current levels of direct investment in Canada. FDI data and statistics cannot accurately show the potential for future investment.

Table 1 Canadian inward FDI from Asia (C\$ millions)

\begin{tabular}{|c|c|c|c|c|c|c|}
\hline Country & 2013 & 2014 & 2015 & 2016 & 2017 & Rank \\
\hline Asia/Oceania & 73,497 & 81,144 & 78,998 & 77,551 & 82,583 & \\
\hline Australia & 5,173 & 6,359 & 9,383 & 11,425 & 11,540 & 12 \\
\hline Bahrain & n.a. & n.a. & n.a. & n.a. & n.a. & n.a. \\
\hline Bangladesh & n.a. & n.a. & n.a. & n.a. & n.a. & n.a. \\
\hline Brunei Darussalam & n.a. & n.a. & n.a. & n.a. & n.a. & n.a. \\
\hline Burma & n.a. & n.a. & n.a. & n.a. & n.a. & n.a. \\
\hline Cambodia & n.a. & n.a. & n.a. & n.a. & n.a. & n.a. \\
\hline China (People's Rep.) & 13,742 & 15,617 & 13,763 & 15,279 & 16,432 & 9 \\
\hline Hong Kong & 13,966 & 14,654 & 11,208 & 12,315 & 12,431 & 111 \\
\hline India & 3,244 & 3,914 & 3,626 & 3,245 & 3,057 & 20 \\
\hline Indonesia & 1 & n.a. & 1 & n.a. & 22 & 51 \\
\hline Iraq & n.a. & -1 & n.a. & n.a. & n.a. & n.a. \\
\hline Iran & n.a. & n.a. & n.a. & n.a. & n.a. & n.a. \\
\hline Israel & 362 & 251 & 243 & 98 & 156 & 41 \\
\hline Japan & 19,519 & 22,184 & 26,452 & 29,759 & 29,632 & 6 \\
\hline Jordan & n.a. & n.a. & n.a. & n.a. & n.a. & n.a. \\
\hline Kazakhstan & n.a. & 2 & n.a. & n.a. & -5 & 57 \\
\hline North Korea & n.a. & n.a. & n.a. & n.a. & n.a. & n.a. \\
\hline Kuwait & n.a. & 1,291 & 2,297 & 1,992 & 1,841 & 26 \\
\hline Kyrgyzstan & 482 & 559 & 499 & 339 & 330 & 40 \\
\hline Lebanon & n.a. & n.a. & n.a. & n.a. & n.a. & n.a. \\
\hline Macau & n.a. & n.a. & n.a. & n.a. & n.a. & n.a. \\
\hline Malaysia & 10 & 5 & 16 & n.a. & n.a. & n.a. \\
\hline Mongolia & 2 & n.a. & 36 & n.a. & n.a. & n.a. \\
\hline Myanmar & n.a. & n.a. & n.a. & n.a. & n.a. & n.a. \\
\hline Nepal & n.a. & n.a. & n.a. & n.a. & n.a. & n.a. \\
\hline New Zealand & 46 & 48 & 45 & 46 & 46 & 45 \\
\hline Oman & n.a. & n.a. & n.a. & n.a. & n.a. & n.a. \\
\hline Pakistan & n.a. & n.a. & n.a. & n.a. & n.a. & n.a. \\
\hline Papua New Guinea & n.a. & n.a. & n.a. & n.a. & n.a. & n.a. \\
\hline
\end{tabular}

Source: Adapted from Global Affairs Canada. Retrieved from: https://www. international.gc.ca/economist-economiste/statistics-statistiques/ outward_inward-actifs_passif.aspx?lang=eng 
Table 1 Canadian inward FDI from Asia (C\$ millions) (continued)

\begin{tabular}{lcccccc}
\hline Country & 2013 & 2014 & 2015 & 2016 & 2017 & Rank \\
\hline Philippines & 51 & 63 & 62 & 1 & n.a. & n.a. \\
Qatar & n.a. & n.a. & n.a. & n.a. & n.a. & n.a. \\
Saudi Arabia & 1,276 & n.a. & n.a. & n.a. & n.a. & n.a. \\
Singapore & 792 & 1,562 & 247 & 321 & 354 & 39 \\
South Korea & 4,127 & 3,522 & 1,413 & 2,515 & 2,660 & 22 \\
Sri Lanka & n.a. & n.a. & n.a. & n.a. & n.a. & n.a. \\
Syrian Arab Republic & n.a. & n.a. & n.a. & n.a. & n.a. & n.a. \\
Tajikistan & n.a. & n.a. & n.a. & n.a. & n.a. & n.a. \\
Thailand & 6 & 7 & 1 & 8 & 23 & 50 \\
Taiwan & 29 & 17 & 130 & 59 & 59 & 44 \\
United Arab Emirates & 10,693 & 11,091 & 9,681 & 17 & 3,874 & 19 \\
Vietnam & n.a. & n.a. & n.a. & n.a. & n.a. & n.a. \\
Yemen & n.a. & n.a. & n.a. & 131 & 131 & 42 \\
\hline
\end{tabular}

Source: Adapted from Global Affairs Canada. Retrieved from: https://www. international.gc.ca/economist-economiste/statistics-statistiques/ outward inward-actifs passif.aspx?lang=eng

Similar FDI data and statistics are not yet available for many countries represented in the Middle East region. The study titled Canada's economic interests in the Middle East (Momani et al., 2013) shows that over the past decade, Canada has substantially increased its trade presence in the Middle East, with exports to the region growing by $168 \%$. The Middle East has become an increasingly important trading partner for the Canadian economy, representing $1.4 \%$ of total Canadian trade, up from $0.6 \%$ in 2002. This growth has been primarily driven by trade with the GCC countries, with total two-way trade increasing by $325 \%$ over the past decade to a total of $\$ 6.8 \mathrm{~B}$ in 2011 . The GCC region alone now accounts for a greater percentage of Canadian trade $(0.76 \%)$ than the entire Middle Ease region did in 2002 (Momani et al., 2013).

Individually, Middle Eastern countries are not recognised as significant contributors of FDI to Canada. Even if these countries were grouped together as countries represented under the Middle East region, they are still not large enough FDI contributors to be recognised on their own. If Canada's foreign trade and investment policies were to include a strategy that considered the benefits of guanxi and wasta in the countries where these concepts are employed, then it is possible that future FDI levels could change.

\section{Conclusions}

The FDI data and statistics presented in this paper would indicate that neither China nor countries from the Middle East region contribute significantly in terms of FDI to Canada. While the data and statistics presented are indicative of current foreign investments, they do not reflect the prospects of future FDI. There remains a great potential for investment in China and countries from the Middle region. China is of significance in this regard as it is currently the second largest economy in the world and poised to overtake the USA as 
the world's largest economy (by gross domestic product levels). Countries from the Middle East region, specifically the Gulf Cooperation Council countries, still control most of the world oil resources and as such have some of the world's highest GDP per capita. Oil rich countries from the Middle East region can contribute to foreign investments that are sizable in proportion to their individual country populations.

For now, guanxi and wasta do not command a high level of influence on the Canadian economy. However, as more Middle Eastern and Asian countries grow and develop their individual economies, the significance of guanxi and wasta to Canada is likely to change. The rise and dominance of the Chinese economy on world trade is almost a certainty given China's economic trajectory. The question becomes, how will Canadian business and industry respond when the USA is no longer the world's largest economy? Greater understanding and knowledge of the guanxi and wasta concepts will serve to give participants a strategic advantage in the conduct of business with China and countries in the Middle East region.

\section{References}

Areekadan, J. (2014) Re: Organizational Culture [Online Discussion Group], 17 September [online] https://landing. athabascau.ca/profile/jareekadan (accessed 17 September 2019).

Baamir, A.Y. (2016) Shari'a Law in Commercial and Banking Arbitration: Law and Practice in Saudi Arabia, 1st ed., Routledge, London, England.

Berry, L.L. (1983) 'Relationship marketing', in Berry, L.L., Shostack, G.L. and Upah, G.D. (Eds.): Emerging Perspectives on Services Marketing, pp.25-28, American Marketing Association, Chicago, IL.

Chaminade, C. and Vang, J. (2007) 'Explaining multinational companies from the developing economies of east and southeast Asia', in Yeung, H. (Ed.): Handbook of Research on Asian Business, Edward Elgar Publishing, Northampton, MA.

Dowling, J. and Pfeffer, J. (1975) 'Organizational legitimacy: social values and organizational behavior', Pacific Sociological Review, Vol. 18, No. 1, pp.122-136.

Fan, Y. (2002) 'Questioning guanxi: definition, classification and implications', International Business Review, Vol. 11, No. 5, pp.543-561.

Fernandez, K.V. and Rosen, D.L. (2000) 'The effectiveness of information and color in yellow pages advertising', Journal of Advertising, Vol. 29, No. 2, pp.61-73.

Flannigan, P. (2014) Re: Organizational Culture [Online Discussion Group], 17 September [online] https://landing.athabascau.ca/profile/pflannigan (accessed 17 September 2019).

Ford, D. (1980) 'The development of buyer-seller relationships in industrial markets', European Journal of Marketing, Vol. 14, Nos. 5-6, pp.339-353.

Global Affairs Canada (2019) Foreign Direct Investment Statistics - Outward and Inward Stocks, 16 January [online] https://www.international.gc.ca/economist-economiste/statisticsstatistiques/outward_inward-actifs_passif.aspx?lang=eng.

Gronroos, C. (1994) 'From marketing mix to relationship marketing: towards a paradigm shift in marketing', Management Decision, Vol. 32, No. 2, pp.4-20.

Guanxi (n.d.a) In Collins English Dictionary [online] https://www.collinsdictionary.com/ dictionary/english/guanxi.

Guanxi (n.d.b) In World Learner Chinese [online] http://www.worldlearnerchinese.com/ content/what-Guanxi.

Harrell, S. (1979) 'The concept of soul in Chinese folk religion', The Journal of Asian Studies, Vol. 38, No. 3, pp.519-528. 
Katz, M.H. (2013) Prayer in Islamic thought and Practice, Cambridge University Press, Cambridge, England.

Legitimacy (n.d.) In Merriam-Webster Online Dictionary [online] http://www.merriamwebster.com/dictionary/legitimacy (accessed 2020).

Modood, T. (2010) 'Moderate secularism, religion as identity and respect for religion', The Political Quarterly, Vol. 81, No. 1, pp.4-14.

Momani, B., Landy, P. and Antkiewicz, A. (2013) Canada's Economic Interests in the Middle East, Canadian Arab Institute [online] https://www.canadianarabinstitute.org/publications/ policy-briefs/canadas-economic-interests-middle-east1/ (accessed 2020).

Ostrowski, P. and Penner, G. (2009) It's All Chinese to Me: an Overview of Culture \& Etiquette in China, Tuttle Publishing, North Clarendon, VT.

Sidani, Y.M. and Thornberry, J. (2013) 'Nepotism in the Arab world: an institutional theory perspective', Business Ethics Quarterly, Vol. 23, No. 1, pp.69-96.

Smart, J. (2012) 'Dancing with the dragon: Canadian investment in China and Chinese investment in Canada', The School of Public Policy, Vol. 5, No. 27, pp.1-20.

Stewart, A. (2003) 'Help one another, use one another: toward an anthropology of family business', Entrepreneurship Theory and Practice, Vol. 27, No. 1, pp.383-396.

Suchman, M.C. (1995) 'Managing legitimacy: strategic and institutional approaches', The Academy of Management Review, Vol. 20, No. 3, pp.571-610.

Wasta (n.d.) Macmillan Dictionary [online] https://www.macmillandictionary.com/dictionary/ british/wasta (accessed 2020).

Wolf, E.R. (1951) 'The social organization of Mecca and the origins of Islam', Southwestern Journal of Anthropology, Vol. 7, No. 4, pp.329-356.

Wood, D.J. (1991) 'Corporate social performance revisited', Academy of Management Review, Vol. 16, No. 2, pp.691-718.

Yao, X. (2007) 'Religious belief and practice in urban China 1995-2005', Journal of Contemporary Religion, Vol. 22, No. 2, pp.169-185.

Yeung, H.W. (2000) 'Limits to the growth of family-owned business? The case of Chinese transnational corporations from Hong Kong', Family Business Review, Vol. 13, No. 1, pp.55-70. 